Portland State University

PDXScholar

\title{
Weaving Urban Webs: Representations of Urban Space in the First Four Issues of Ultimate Comics: Spider-Man
}

Cordelia Albertson

Portland State University

Follow this and additional works at: https://pdxscholar.library.pdx.edu/honorstheses

Part of the English Language and Literature Commons Let us know how access to this document benefits you.

\section{Recommended Citation}

Albertson, Cordelia, "Weaving Urban Webs: Representations of Urban Space in the First Four Issues of Ultimate Comics: Spider-Man" (2020). University Honors Theses. Paper 913.

https://doi.org/10.15760/honors.934

This Thesis is brought to you for free and open access. It has been accepted for inclusion in University Honors Theses by an authorized administrator of PDXScholar. Please contact us if we can make this document more accessible: pdxscholar@pdx.edu. 
Weaving Urban Webs: Representations of Urban Space in the First Four Issues of Ultimate

Comics: Spider-Man

by

Cordelia Albertson

An undergraduate honors thesis submitted in partial fulfillment of the requirements for the degree of

Bachelor of Arts

in

University Honors

and

English Literature

Thesis Adviser

Dr. Susan Kirtley

Portland State University 
Abstract

As the anthology Comics and the City explores, cities have been central to comics since the beginning of the modern medium (edited by Ahrens \& Meteling, 4). Yet, scholars have remarked little on the relationship between superhero identities and urban space. Peter M. Coogan's article, “The Hero Defines the Genre, The Genre Defines the Hero," in the anthology What is a Superhero?, cites an urban setting as a secondary identifier of the superhero genre and the superhero identity, but he makes no other remark on this facet in the article or his other work (edited by Rosenberg, 8). Much of the works existing on the subject of urbanism and the superhero identity in comics studies only relate to the subject tangentially. Due to the limitations of this thesis project, I use a singular superhero comic as an initial case study, if you will, to provide a launch point for future research. Investigating the first four issues of Ultimate Comics Spider-Man, words by Brian Michael Bendis and art by Sara Pichelli, I find that Miles Morales's identity as Spider-Man is heavily defined in how he is depicted in relationship to crowds, how his powers allow him to traverse the city, and how crucial moments in his character development inhabit marginal spaces both in his version of New York and in the comics as a medium. Ultimately, my findings suggest that the urban space and the comics medium provides the visually demonstrable liminal spaces that define key aspects of Miles's superhero identity. 
Introduction

As the anthology Comics and the City has explored, urban spaces have been central to comics since the beginning of the modern medium (edited by Ahrens \& Meteling, 4). Yet, scholars have remarked little on the relationship between superhero identity and urban space. Peter M. Coogan's article, “The Hero Defines the Genre, The Genre Defines the Hero" in the anthology What is a Superhero? (edited by Rosenberg, 8), cites an urban setting as a secondary identifier of the superhero genre and the superhero identity, but he makes no other remark on this facet in the article or in his seminal work Superhero: The Secret Origin of the Genre. In the field of Comics Studies, much of the works existing on the subject of urbanism and the superhero identity only relate to the overlapping of the subjects tangentially, especially in regard to specifically comics-focused study. Due to the limited nature of this thesis project, I decided to use a singular superhero as an initial case study, if you will, to hopefully provide a launching point for future projects. Given the iconic nature of the relationship between Marvel Comics and New York City, I chose to use one of their most iconic superhero narratives - and one of their most New York centric superheroes - to investigate the relationship between the city and the superhero genre: Spider-Man, specifically Miles Morales from the Ultimate Comics imprint. In his essay "II am New York," Jason Bainbridge explores the close-knit, iconic nature of the relationship between the real New York city and Spider-Man, his argument stressing the extradiegetic understanding of the character. That being said, as demonstrated in the Robert Persichetti animated film Spider-Man: Into The Spider-Verse, there were many "Spider-People" from different Marvel Universes for me to choose from, the term being diegetically coined by Miles Morales in the film. Choosing Spider-Man comics as my subject led me to a seemingly endless series of choices to determine exactly which version(s) of Spider-Man or Spider-Woman 
to select and then to choose how many issues to analyze. The main deciding factors for me work were how prevalent the urban environment was in the comic, whether the character had already received attention in academia, whether they had significant relevance to current social and socio-political events, and which narratives would be the least complicated to track. My search eventually led me to the first four issues of Ultimate Comics Spider-Man (writer Brian Michael Bendis and artist Sarah Pichelli) featuring Miles Morales as the main character. In particular, I searched for answers to the following questions: What aspects of the city are prevalent in these comics, and what do they provide the narrative and the superhero in question? What about this particular relationship helps to define the superhero identity-both for my particular chosen material and possibly as a whole? Therefore, my project consists of a formal analysis investigating the relationship between the superhero identity and urban spaces in the first four issues of Ultimate Comics Spider-Man. Addressing works like Ben Highmore's City Scapes and the anthology Comics and the City (Ahrens and Meteling), I review literature that contextualizes my work within current Comics Studies discourse. Within said context, I find that Miles Morales's identity as Spider-Man is heavily defined in how he is depicted in relationship to crowds, how his powers allow him to traverse the city, and how crucial moments in his character development inhabit marginal spaces both in his version of New York and in the comics as a medium. Ultimately, my findings suggest that the urban space and the comics medium provides the visually demonstrable liminal spaces that define key aspects of Miles's superhero identity.

\section{Methodology}

First, establishing a concept of urbanism within the terms of what superhero comics can depict immediately creates a limitation on what I as a researcher and comics analyst can feasibly 
include in my analysis. The panels in comics are limited to two-dimensional space and the illusion of depth, implied movement, and narrative action created largely by the juxtaposition of panels. These limitations allow my analysis to focus on the details of the city included in these panels. Using Ben Highmore's Cityscapes to guide my analysis, I explore the images and text within these comics as they display the experience of urban density as can be found on the comics page (5). Highmore bases his analysis in cultural studies, and while many would argue that this is a limiting scope, I find the mediums he investigates appropriately similar to my own. While examinations of urban space in comics often revolve around urban architecture, and appropriately so, examining population and social density as it appears on the comics pages requires me to investigate more than urban edifices. My analysis examines other aspects of urban density as demonstrated in comics: people (particularly crowds); spaces between buildings such as alleys and streets; interior urban spaces; the sound effects representing sounds of the city; and artifacts that come with these spaces such as graffiti, dumpsters, cars/vehicles, food carts, etc-in the context of Miles's superhero journey. I will also be examining text in speech balloons related to the characters' experiences of urban space. The manners in which I analyze what is depicted and written will be informed by Charles Hatfield's system of analysis: page layout, panel composition, breakdown, and image/text interplay (as demonstrated in his work "Ways of Reading Comics: A Page from Black Widow”). Some of the language and theory I have included are supplied by works such as Will Eisner's Comics and Sequential Art and Scott McCloud's Understanding Comics. These inform the basis of my analytical praxis, while my interpretational praxis lies within varied critical works. 


\section{Literature Review}

Considering the state of Comics Studies as a new field that lacks a sense of unified disciplinarity, through my research I hope to represent the varied backgrounds of comics scholars. While the bulk of Comics Studies works today have been produced by those from a literary or film studies background, other important compositions have also focused on comics as pop cultural items and as sequential art (Steirer, 263-285). In an attempt to include these various forms, I've investigated a wide range of commentary and criticism on the relationship between the superhero identity and urban space. Most of the works I have found relevant to my project, however, have been those from literary studies, cultural studies, and formalist Comics Studies.

The Anthology Comics and the City edited by Arno Meteling and Jörn Ahrens has been a key resource in my research and contains several works exploring conjoining themes between comics and the city. Some explore how the very format of comics must be navigated with a wandering or dispersed gaze (Balzer 26). Some discuss how the comics form refuses to be read through a panoptic gaze via Michel De Certeau's "rhetoric of walking” (Frahm 38). Balzer and Frahm's works suggest that the inherent structure of the comic page ties itself to the experience of urban density. In particular, these works seem to suggest a correlation between the comics form and the embrace of the non-hegemonic gaze. As such, articles directly correlate to Highmore's discussion of legibility versus illegibility. Highmore's work presents this notion of "illegibility" in the context of the communities labelled as deviant or "other" that often inhabit urban spaces (7). Indeed, he proposes that attempting to make the city "legible" by compressing its diverse and multifaceted realities is an act of erasing marginalized cultures and identities. In the context of Highmore's work, Balzer and Frahm's works indicate that comics inherently embody the "illegibility" of the city. The demand of the dispersed gaze encourages me to 
examine how the comics I'm investigating influence the gaze of the reader and the particular ways in which the creators use the urban setting to their advantage.

Where Balzer and Frahm's works did not discuss superhero comics, Jason Bainbridge's "I am New York" from the same anthology examined the relationship between Spider-Man (ie the Marvel Universe) and New York. He found that through their fictional relationship, Marvel and New York have become a mutual lens of understanding for each other, as readers view New York through their understanding of Marvel and New Yorkers come to view Marvel through their understanding of New York (175). This simultaneously diegetic and extradiegetic nature of Marvel's New York lends additional complexity to how Marvel's fictionalized urban spaces and their comics define their superheroes - and how these characters define their particular renderings of New York. Furthermore, Bainbridge's work reminds the scholar that while comics can be examined in a formalist or literary manner, they are cultural items that do not exist in a vacuum, and, therefore, their impact on the real world and the real world's impact on comics must not be ignored. Because Bainbridge focused on Peter Parker as a cultural icon, his work doesn't factor in the significance of Parker's identity as a young white man. Meanwhile, my examination will focus on a character of marginalized identities and will therefore include how the context of Miles Morales's identity as a member of a socially marked demographic shifts the meaning of form and story in his comics diegetically and extradiegetically.

Much of my work investigates diegesis, but understandably, diegesis does not operate the same way in comics as it does in purely textual pieces. Because of the often heavily visual nature of comics, the understanding of narration and what pertains to the plot shifts. Pichelli's art in the four issues I'm investigating explores an internal and external lens of diegesis, as revealed in the relationship between the monstration and the ocularization of the panels in the comic. Derik 
Badman borrowed these terms from literary theory and film theory respectively in his article

"Talking, Thinking, and Seeing in Pictures: Narration, Focalization, and Ocularization in Comics Narratives" (97). Badman's use of monstration refers to the narrative level of the image in comics, and, in tandem with ocularization, is essentially what produces the visual narrative in comics. Badman's work investigates the crucial relationship between panel composition and the sequencing of panels and how it creates visual narrative in comics. In particular panels, Pichelli's work demonstrates a subtle combination of external ocularization and monstration to create panels where the focalizer is simultaneously extradiegic and diegetic by composing panels with crowds in a manner that suggests that the reader is a member of these crowds, in turn, implicating the reader as a part of the experience of urban density.

Some contextual changes will appropriately affect my interpretation. Highmore specifically mentions superheroes in relation to mobility in its sixth chapter, providing insight into the significance of the superhero's hypermobility in comics (124). As described by Bainbridge, Spider-Man is so often depicted as posed sprawling above the skyscrapers of New York. Miles Morales has been no different. As Highmore describes, in silver age comics, cities are often depicted as the source of a kind of individual impotence, as being the stifling force, rendering citizens helpless (128). A superhero's mobility thus becomes a fantasy to be lived, and a means of overcoming the city's stifling influence. Where superhero hypermobility used to tackle the feelings of impotence felt by men in the dense and overwhelming environment of the city, from the metaphorical emasculating effect of the urban office job, in today's political climate, the significance of hypermobility for Miles Morales shifts towards depicting marginalized people as defying the stifling hegemonic urban structures that hamper often their sociocultural and socioeconomic mobility. 
In turn, I find it crucial to investigate the relationship between Miles's powers and his racial identity—particularly his power of invisibility. Invisibility and blackness have a particular sociocultural and literary history in the sense that non-black American people and institutions have consistently ignored and shoved black bodies and communities to both the literal and figurative margins of society for centuries. Simultaneously, these people and institutions mark black bodies as "other" from the assumed white norm. Racism today is still a complex system of invisibility and hypervisibility imposed on Black Americans by white hegemony. In "Invisibility Embraced: The Abject as a Site of Agency in Ellison's Invisible Man," Shelly Jarenski explores the dynamics of race, gender, invisibility, and the abject. In particular, Jarenski argues that "In the novel, invisibility allows Ellison to create a black male subjectivity that is fully outside of visually constructed white, hetero-male hegemony," explaining that in examining Ellison's Invisible Man through Judith Butler's work with Julia Kristeva's notion of the abject-the idea of bodies that are only defined insomuch as they are used as an "other" by which to compare and define "dominant" (male, cisgender, straight, white) culture—abjectness or invisibility becomes a manner in which the narrator subverts visual constructions of black bodies as a stereotyped "other" within a "white, hetero-male hegemony" (86). In the context of Miles as Spider-Man, this same concept is executed through his superpowers. Miles's literal invisibility, along with his other powers, becomes a key manner in which he navigates the city and, in turn, subverts some aspects of the oppressive systems within it. As such, embracing his powers allows him to move through the literal and figurative liminal spaces of the city. This suggests that the prime means through which Miles subverts the power of these imposed structures and thereby engages in his own agency is through embracing the marginal nature of his identity, through refusing to comply 
with the structures imposed upon him without fleeing society itself — and by doing so, demands that the gaze imposed upon him shifts to comply with his identity.

The Inhospitable Urban Imaginary

One of the key manners in which the city operates within these four issues is to create or replicate various urban imaginaries - particularly that of the city as a hub of crime and iniquity that the superhero must save. All the creators' work in this comic, however, provides a more complex urban imaginary, one where, yes, aspects of Miles's New York are inhospitable, but they are made so by external forces. Through the character of Aaron Davis (Miles's Uncle), they also pose that these dangers are products of a system of oppression imposed upon urban spaces that particularly affect those of marginalized identities: in this case, young Black American boys. This is where the imposed structure of the city is first suggested to the reader. Through the perspective explained by Aaron Davis (also the Prowler), this comic constructs a system of oppression reliant on marginal location and poor education, suggesting that if Miles takes the opportunity to attend the charter school which he is accepted into at the beginning of issue one, he will be able to affect change by escaping a never clarified spatial influence implicitly anchored in Brooklyn.

Aaron Davis's particular environment as shown in the first issue of Ultimate Comics Spider-Man, demonstrates his view of himself and his role in Brooklyn. In the first issue on pages 13-19, Miles visits his uncle Aaron in a run-down Brooklyn apartment. In the first panel on page 13, the hallway is completely empty aside from Miles himself. The irregular crosshatching on the walls indicating dirt and oils, the lines indicating cracks in the ceiling, the spartan lighting, the heavy shadows, and the sickly yellow-green color covering the walls and 
ceiling all lend an atmosphere of grime and grunge to the interior of this building (13.1-4, see figure 1). Apartments are products of urbanism, they conserve horizontal space and comply with the pattern of stretching vertically in order to fit more bodies over a smaller amount of surface area. This space is clearly also a product of neglect, lacking maintenance and care. The hall being the main shared space on each floor of the building, it's crucial to consider how Pichelli
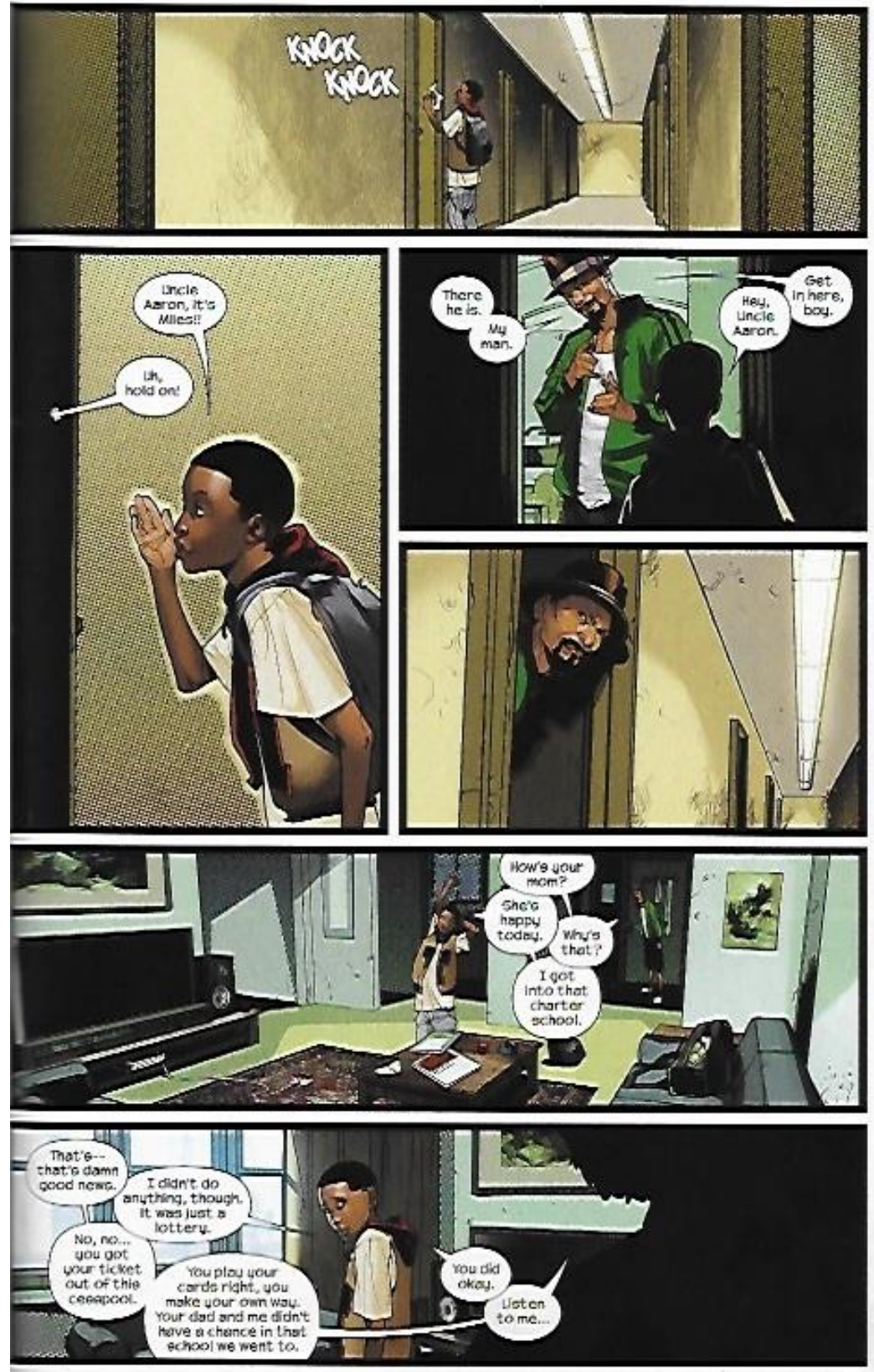

Figure 1 - Issue 1, Page 13 of Ultimate Comics Spider-man from Brian M. Bendis and Sara Pichelli; Ultimate Comics Spider-Man, Vol. 1. Marvel Comics, 2012. and Justin Ponsor's (colorist)

work portrays these halls as a

spartan, ill-kept, unwelcoming

space, discouraging people from

staying in them and thereby

discouraging any interpersonal

interaction. So not only is the

space poorly kept, it encourages

isolation. This sense of isolation

is then laced with a hint of fear

and vigilance as Aaron glares

down the hallway in panel four,

as if ensuring no one is watching

or listening. His action speaks to

his awareness of his

surroundings - he believes that

that even the hallway leading to

his home isn't entirely safe. 
Aaron's action in turn validates any assumptions or judgements the reader may have made about this building and this part of town. This moment demonstrates how the city poses danger to its own inhabitants.

The discussion Aaron Davis has with Miles in the following pages further ratifies his claim that "this cesspool" (Brooklyn assumedly) perpetuates danger in the city (13.6). Miles's uncle tells him that Miles has a "ticket out," that if he does things right he can "make [his] own way." Uncle Aaron's words echo Miles's mother's in the second panel on page twelve, where she says, "You have a chance" not once, but twice. Their words send a clear and urgent message that Miles needs to take this chance to escape Brooklyn as a spatial source of oppression (12.6). Furthermore, the way in which Aaron is depicted in relationship to Miles in the last panel on page thirteen demonstrates his Uncle's particular relationship with this dangerous aspect of the city. The relative width and short height of this panel draws attention to the scaling of light and dark from left to right. On the left, we see the light Pichelli and Ponsor have portrayed shining through the windows - the brightest point in the panel. On the far right, Aaron is represented by the silhouette of his chin and shoulder, comprising the darkest point of the panel. Miles stands between these two points, between the light and the dark, looking back at his uncle, saying "You did okay," half-heartedly challenging his uncle's reasons for supporting Miles getting into the charter school his parents pushed him towards. The information we gain in the first panel on page thirteen clarifies this interaction. Here, the two characters are drawn over a background of white accented with light-blue Ben-Day dots, and Miles's uncle explains why Miles needs to take this opportunity at the charter school. He says: "We had to fight. Boys shouldn't have to fight the way we had to. You shouldn't have to see half the stuff we did," describing that his experience growing up was one full of struggle, full of fighting, and full of things children 
shouldn't have to see or do. Uncle Aaron's description seems to be deliberately vague, as if he won't even dare mention the things he went through. Nonetheless, Aaron implies his belief that he is a product of his environment, and his silhouette in the last panel on page thirteen reflects that sentiment. He encourages Miles to take advantage of this opportunity and make use of his agency, and then insists that he doesn't have to bend to the alternatives. Specifically, Aaron says, "You make the world the way you want it to be, not the way it is. / You make it. Don't let other people make it for you" (13. 1-2). He insists that other people will exert their own agency (which could impact Miles) and Miles's only means of agency is the road of a good education to the end goal of escaping Brooklyn. Aaron Davis implicitly and explicitly poses the space of Brooklyn as a source of oppression, and he believes that the only way Miles can hope to subvert that oppression to any extent is to escape the oppressive environment.

Understanding the context of Aaron's reasoning, and knowing that he is the Prowler, a supervillain, pages 13 and 14 demonstrate textually and visually, that, due to others in this city exerting their agency directly or indirectly upon him, he was forced to become a part of a dangerous underbelly of the city and he is verbally pushing Miles towards the light. Good education, according to the adults in Miles's life, circumvents aspects of this power dynamic. Attending this charter school, to them, will allow Miles to navigate the sociocultural and socioeconomic cityscape of New York with greater success than if he attended a public school like the previous generation - and it's important to note that the former is also outside of Brooklyn. This description of Brooklyn reflects the affects Highmore describes as hegemony makes "legible" or simplified the diversity of the city in how it labels the marginalized as "wayward." Miles's acquisition of powers and his eventually role as a superhero, however, highlights a more complex system of oppression and the possibilities to subvert aspects of it. 


\section{The Urban Gaze}

There's something crucial and consistent in several panels throughout these four issues that's at the heart of the experience of urban density — at the core of the densely packed buildings, streets, grunge, and petty crime. Urban space is defined by its density of people and one of the key biproducts of that density is crowds. Panels in these comics that depict crowds are frequently and consistently structured around the reader's gaze — and in turn pose the readers as witnesses to these moments in Miles's story. In particular, certain panels throughout these four issues consistently take on the view of the spectator within a crowd. These crowds emphasize a clear experience of density through swarming masses of people in public spaces. These particular depictions of crowds can be seen as early as page ten of issue one to as late as page 18 of issue four $(1.10 .5,4.18 .8)$. The visual perspective taken is head-on into the crowd, rather than depicting the subjects from above them-encouraging a sense of detachment as Will Eisner describes in his work Comics and Sequential Art when discussing the angles at which images are directed at a subject in the panel (92). Where often the perspective of a panel is treated similarly to a clean camera shot with nothing interrupting the view from the subject, the perspective here is instead treated like another person in the crowd - as can be denoted by the sleeved elbows of passersby on both edges of the panel. In extension, the reader is encouraged to take on this perspective as if they are members of the crowd. There's nothing particular about the external ocularization, the story being told from a visual perspective external from Miles (Badman 97). It is the particular way the ocularization is presented, treating the reader as a participant that makes these panels narratively remarkable. Panels in all four of these comics demonstrate such a practice of an implied extradiegetic ocularization, but a consistent pattern becomes apparent 
while examining the points in the story where Miles first sees the Human Torch and Iceman in the street and when he performs his first heroic act.

The moment Miles sees Ice-man and the Human Torch on page 14 of issue two, something shifts in Miles's conception of what it means to be genetically altered, and what it means to be a superhero (2.14.1, see figure 2). Where just a few pages before, Miles was agonizing over how horribly mutants are viewed in New York, seeing these superheroes (Iceman in particular being a mutant) challenges his preconceptions. It is fair to assume that the two

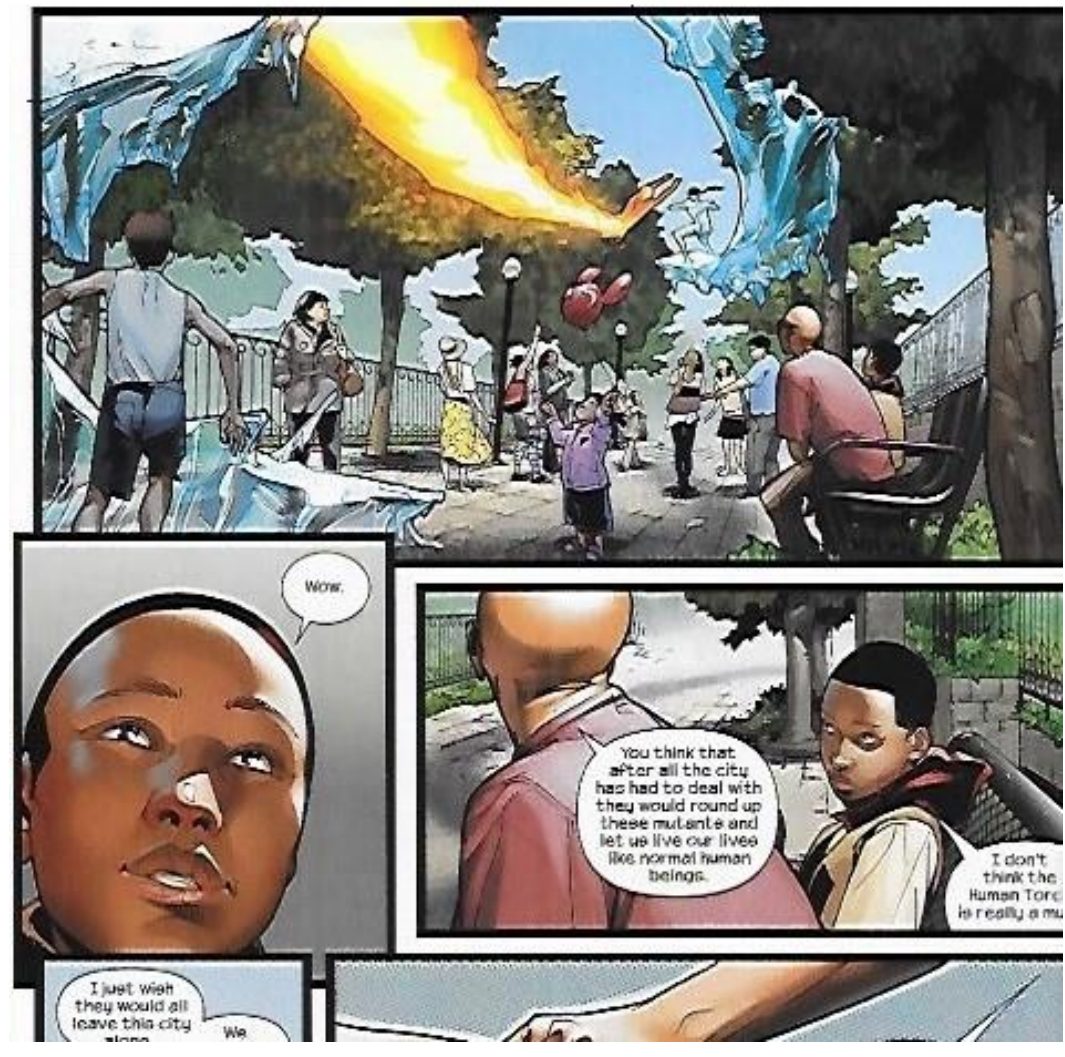

Figure 2-Issue 2, Page 14, Panels 1-3 of Ultimate Comics Spider-man from Brian M. Bendis and Sara Pichelli; Ultimate Comics Spider-Man, Vol. 1. Marvel Comics, 2012. superheroes are on their way to participate in the events leading up to Peter Parker's death, but, as I discuss in my section on navigating the city, they navigate the city as if simultaneously apart of and apart from the crowd in which the reader participates. Frahm's exploration of Certeau's work explains how comics pages do not use the panoptic gaze, but rather embrace the dispersed gaze - one that also participates in the street level of urban spaces (43). In such a context, the manner in which Ice-man and the Human Torch are depicted interacting with the urban space in this work could be misconstrued as them exerting an ability to impose a panoptic gaze upon the city. However, the composition of the panel is such that they 
are one of many subjects from a street-level dispersed gaze. The ocularization of the page suggests that instead, the reader, posed as a street-viewer, is observing with a dispersed gaze upon the superheroes, suggesting that their roles as superheroes are one of many integral pieces of this New York. Their navigational abilities, however, as the trails of ice and fire suggest, are also different from those who walk the streets of the park. Their position above the crowd does not suggest to the reader a feeling of vulnerability as described by Eisner in reference to images depicted from low angles (92). In fact, the reader can see the street and the sky through which the superheroes traverse due to the one-point perspective. The superheroes, rather, act as another dynamic of the space in a complex relationship that is simultaneously within and outside of the city as a social entity. Miles reacts in the subsequent panel, where his face is depicted gazing upwards as light from the sun shines on his face and over his eyes (2.16.2). His singular line, "Wow," combined with his expression and the lighting suggests that this is a moment of hope for him, that though he has powers, though he is different, he could be like the heroes he just saw. His response, when compounded with the information from the previous panel, suggests a sense of being a part of something much larger and much more complex than oneself, all demonstrated through the particular spatial and social identity of New York as a city.

The pages leading up to Miles's first heroic act in issue three depict Miles and his friend Ganke mid-stride on a sidewalk, a juxtaposition that emphasizes the nature of the superhero dual identity. Most notably, after the establishing first panel on page seven, these two supposed main subjects of panels two and three take up very little space or detail in comparison to the rest of the compositions. Their words move the action of the plot along, but the most prevalent visual subjects consist of the other people and objects occupying the street. The depth of focus emphasizes the urban markers in these panels: the people, the vehicles, the stop lights, and the 
buildings in the distance and on either side of the street. While not heavily crowded, Miles and Ganke blend in rather poignantly with the people in the street as the panel emphasizes the external ocularization, the focus on that which is outside of the main character, and yet the fact that Miles is still a part of the crowd. The sound effects imitating the sound of a fire engine siren then add another layer to this clear emphasis on the setting in which Ganke and Miles are placed. These are normal sounds to hear in an urban setting on a regular basis. For most in such settings, a siren would be a signal to pull over, to stop and watch but remain uninvolved. For Miles and Ganke, it is the call to action, the shift in the environment that brings the focus back onto Miles

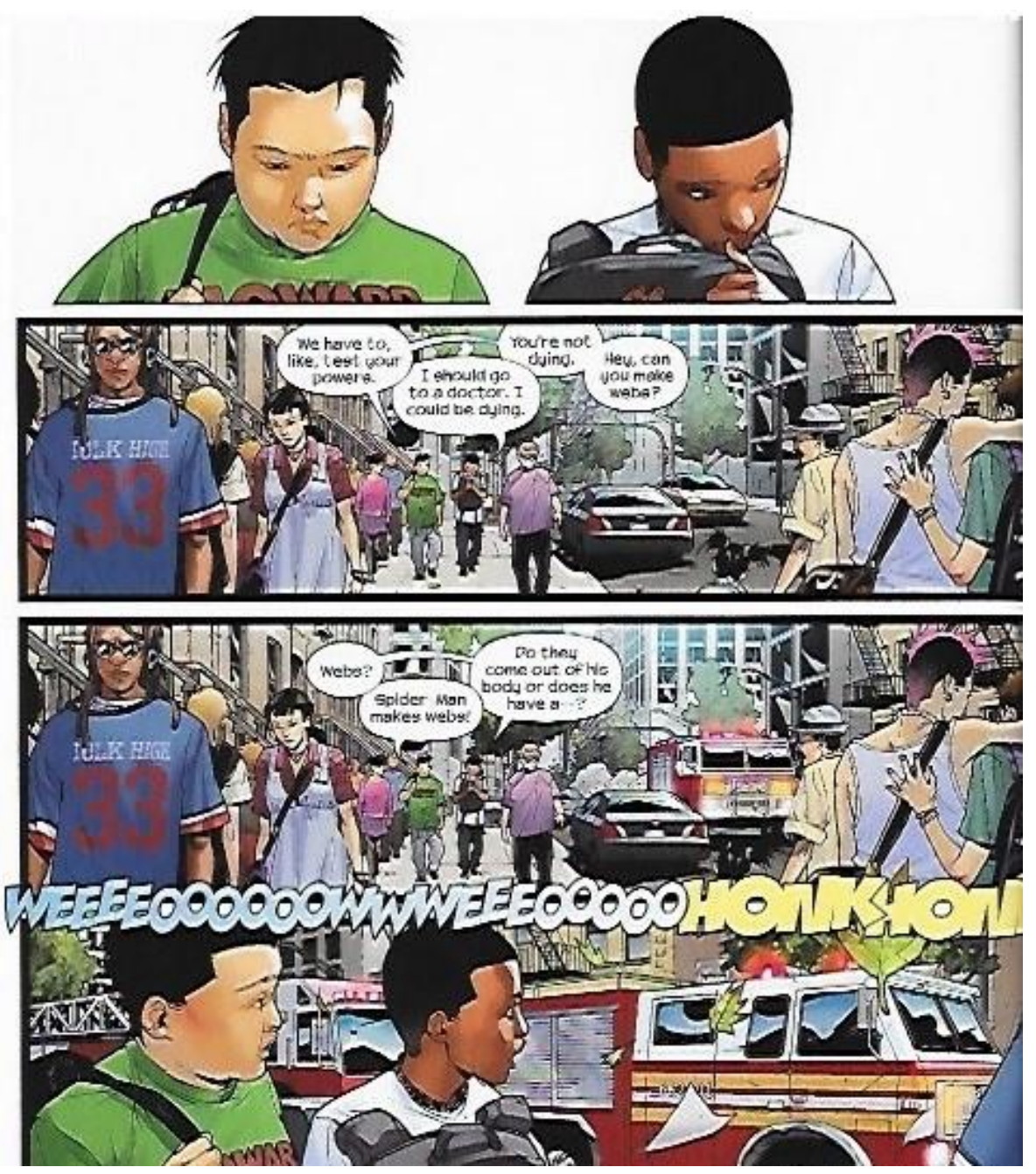

Figure 3 - Issue 3, Page 7, Panels 1-4 of Ultimate Comics Spider-man from Brian M. Bendis and Sara Pichelli; Ultimate Comics Spider-Man, Vol. 1. Marvel Comics, 2012. and Ganke as they are

drawn to the burning

building on page eight.

The reader sees them

amidst the crowd in

panel two and, in the

third panel, Miles, his

head breaking through

the top panel border (i.e.

drawing the reader's

attention to emphasize

the significance of the

panel), makes the

decision to use his

powers the way a 
superhero often does: to help others. Miles's intent, as demonstrated in his lines in panel one of page eight, revolves not around glory but in the ability to act and have greater agency in a situation where others are far more limited. He says "People will see me," demonstrating his fear of being revealed as a genetically altered person, his fear of differentiating himself from the norm - from the crowd, an act particularly dangerous for a young Black boy. Yet, in panel three and throughout the next six pages, Miles takes a preliminary step outside of the crowd and towards his superhero identity by accepting the call to a selfless act of heroism (Rosenburg and Coogan, 4). The urban setting is crucial in providing an environment that clearly demonstrates the complexity of the superhero identity, which relies upon the premise that the superhero simultaneously acts as an agent within and outside of the masses - they are "other" and yet they must be pro-social. Urban density, as represented in Ultimate Comics: Spider-Man, therefore strengthens the demonstration of the superhero identity (that which is apart from the common masses) in juxtaposition of the secret identity (that which is a part of the common masses). These panels consistently demonstrate an experience of urban density throughout Miles's journey in becoming a superhero, particularly positioning the reader's gaze within that context, treating them as a member of the crowd and temporarily posing the reader as both a diegetic and extradiegetic focalizer. The significance of encouraging the reader to temporarily become immersed in the visual narrative in this manner, is that it emphasizes the feeling of being a member of a crowd - of being a body within a dense collection of people, particularly when Miles uses his powers in a pro-social manner. Through these panels, crowds are more than a reminder of density - they are a reminder of belonging to something greater than oneself. However, when Miles answers a call to action while walking down the street in Brooklyn, the juxtaposition of the panels where he acts as a member of the crowd to the panels where he acts as 
an outside agent demonstrate a particular role in this greater something; one that reinforces the nature of Coogan's dual identity as brought out by the call to the superhero mission. It is Miles's ability to navigate the city that demonstrates how his unique position operates.

\section{Super-Navigating the City}

Miles's powers act as an external and internal demonstration of the dispersed gaze, of his ability to navigate New York without imposing a panoptic gaze upon it. This is demonstrated almost immediately after Miles gets his powers in issue two. The issue begins with a panel focused more on the setting rather than on Miles himself. Along with the caption announcing that the reader is returning to Miles's story in "Brooklyn, New York," the panel has a very deep depth of field, showing clear features on the faces of the figures closest in the foreground. Pichelli has placed other fixtures of the city street clearly on display: windows on the buildings surrounding the crowd, taxis and cars in the street, poles of traffic lights and streetlamps, trees in the sidewalk strips, even litter on the sidewalk. While this is an effective tactic for reestablishing the setting, and, in extension, re-immersing the reader in the story, it is also crucial for the following demonstrations of Miles's powers as it establishes the experience of urban density in the following pages. It is that experience of density that creates the obstacles Miles overcomes with his new powers.

In panel four on the same page, the dense nature of the city confronts Miles with an obstacle as two people step into his path carrying a big, flat-screen TV (see figure 4). The panel depicts Miles on left with only a portion of his body displayed — and in heavy shadow at that. In comparison, the right side of the panel depicts the whole of the TV and the bodies of those carrying it in bright light, drawing the reader's eye to focus on them as an obstacle rather than on 
Miles. The shape of the panel border also emphasizes this focus by making the right end wider than the left, using a slanted panel border. Ramping up the energy and dynamism of the panel, this diagonal line works in tandem with Mile's body breaking through the lower panel border of panel four from panel five. The beige outline surrounding the smaller Miles mimics the color of the background in panel five, supposedly anchoring Miles's body (in this instance) at the apex of a parabolic leap above the the television screen. His body in panel five breaking the border of the previous panel serves to blur the line between the individual moments. What McCloud would

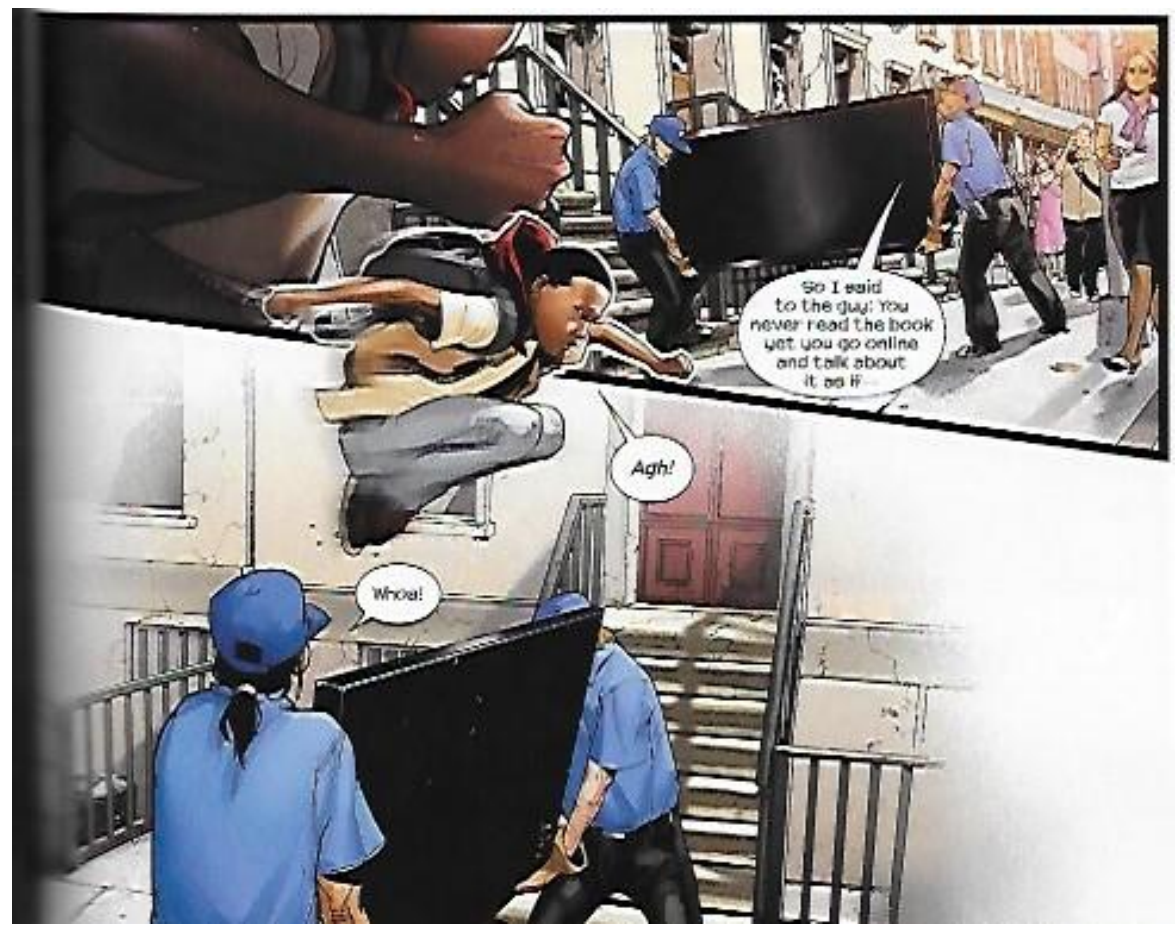

Figure 4 - Issue 2, Page 1, Panels 4-5 of Ultimate Comics Spider-man from Brian M. Bendis and Sara Pichelli; Ultimate Comics Spider-Man, Vol. 1. Marvel Comics, 2012. describe as an action to

action transition breaks

down in this context, demonstrating the nature of Miles's powers (70).

Miles's powers necessitate the dispersed gaze (Balzer 26). The sequential relationship between panels four and five benefits from a gaze that notes the foreground and background of panel four and quickly moves on to Miles's figure breaking in from panel five. Such a demonstration also acts as an externalized expression of the nature of Miles's powers: the reader's gaze reads the page in this manner partially because it is the manner in which Miles's powers permit him to navigate the city as a superhero. His powers permit him to operate within the urban space as an agent outside of the typical systems of 
navigation — or, in the context of Jarenski's work, outside of the constructed hegemonies within the urban space.

Miles's invisibility allows him to escape situations that would otherwise leave him in a position of vulnerability. It allows him to traverse the terrain of the city as a subject outside of the hostile hegemonic systems present in the urban space without necessarily leaving the urban space in its entirety. After he sticks his landing on page two of issue two, the response of the people around him reveals these hegemonies particularly in relation to mutants and genetically altered people. In panel four, the reader looks out into the street, into the faces of the crowd in front of which Miles turned invisible. Through their speech balloons, the reader gains insight into
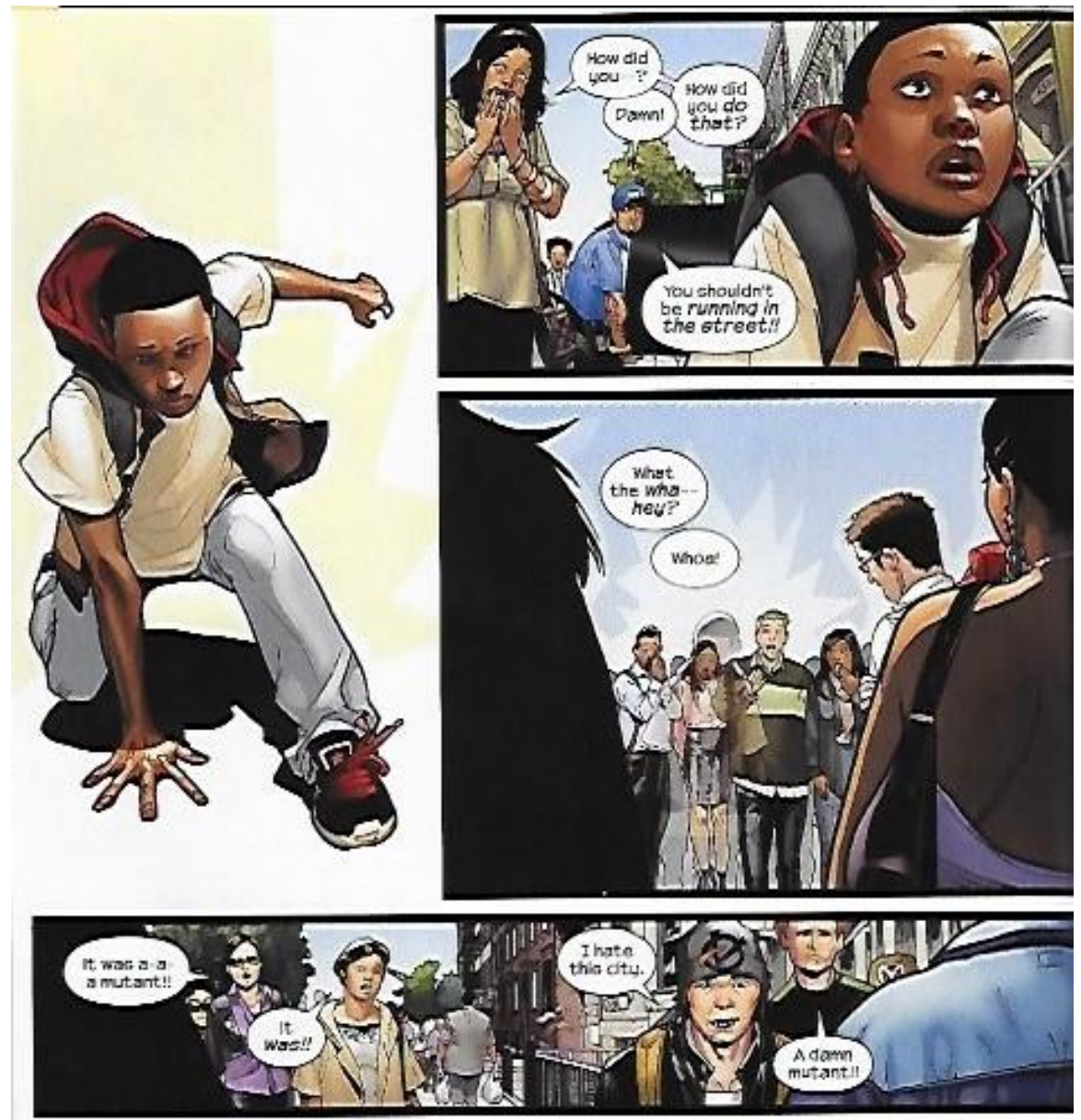

Figure 5 - Issue 2, Page 2, Panels 1-4 of Ultimate Comics Spider-man from Brian M. Bendis and Sara Pichelli; Ultimate Comics Spider-Man, Vol. 1. Marvel Comics, 2012. the stereotypes and

general oppression

mutants face in this

version of New York (see

Figure 5). Some people in

the crowd are simply

surprised and taken

aback, while others make

remarks of derision such

as, "A damn mutant!!"

and "I hate this city." The

remarks of surprise

indicate that mutants are

the "other," or "abject" as 
discussed in Jarenski's work (86). That which is abject is used to identify that which is marginalized by the dominant culture only insofar as it used to define the dominant culture itself. The remarks of derision indicate the ways in which mutants are defined and stereotyped in order to define this hegemonic norm - they are not simply mutants, they are "damn" mutants, posing them at least as an annoyance, if not a threat. They are also referred to in relationship to New York, "I hate this city" indicating that the city's relationship with mutants is uniquely tied to mutants. Most likely, it refers to the large amounts of activity involving mutants and genetically altered people in New York specifically. It's an odd dichotomy when the inhabitants of a city define a group as "other" and yet that urban space cannot be defined without that group. Somehow, "normal" humans are the unmarked and assumed norm, and yet mutants and genetically altered people are part of what makes Marvel's New York what it is - and they do so by operating outside of this hegemonic norm with their superpowers as Miles does in panel three. He disappears before anyone can call on any regulating institutions, escaping both the gaze of the hegemonic norm and any punishments enacted by the oppressive systems that enforce it.

Crowds and groups of people in Ultimate Comics Spider-Man operate in this multifaceted way - both as representations of the city as an urban community and as the oppressive urban hegemonic norm; as entities of acceptance and rejection, of being a part of and being a part from. This seemingly contradictory relationship demonstrates one of the key manners in which urban spaces differ from their rural counterparts: the conglomeration of vast amounts of people with greatly varying identities into a limited physical space, the resistance to that conglomeration by means of marginalization, and the efforts made to resist that marginalization all at once. As a mutant and a young Black Latino American boy, New York’s hegemonic systems simultaneously resist and depend on Miles (particularly his marginalization) in order to maintain 
their constructed rendering of "norm" and "other." Yet, as with other superheroes, it is through his powers that Miles can define himself in a manner that supersedes the definitions imposed on him and operate outside of the hegemonic system that seeks to oppress him.

The Margins of the Superhero Identity

A key dynamic that appears within the first four issues of Ultimate Comics: Spider-Man is how Miles constructs his relationship between himself as a superhero-specifically as a genetically altered person — and New York city. The basis of this dynamic becomes clear in issue two, when Miles is confiding in his friend Ganke about his new powers. On page ten of the issue, Miles gives a clear picture of the relationship between mutants of this world and the governing powers - explaining how they are ostracized and put into "military concentration camps." Most poignantly, he puts the identity of being a mutant and the identity of being a New Yorker at odds with each other, saying "A mutant drowned this city. You do not get to be a mutant in New York City!!” Miles is referring to prior events that eventually culminated in the Ultimatum storyline, where Magneto, a mutant, managed to obtain Thor's hammer and, in combining it with his own powers, reversed the earth's polarity (Loeb \& Finch). This absolutely devastating event in the Ultimate series particularly bombarded New York City with various natural disasters, eventually culminating in a tsunami putting all five boroughs under water. Ultimatum is just one example of why the human world of Marvel remains at odds with mutants and superheroes in general, but in Miles's memory, it seems to be one of the most powerful. He particularly poses that these two identities - that of New Yorker and that of mutant — cannot coexist, making "mutant" an "other" by which to define that of New Yorker within a hegemonic structure. Yet, mutants and genetically altered superheroes are an inextricable aspect of Marvel's New York; 
they are a defining piece of it—and within the context of Bainbridge's "“I am New York", so many Marvel superheroes also act as a lens of understanding between Marvel's New York(s) and the real New York (Ahrens \& Meteling, 175). Indeed, this seems to textually demonstrate a key aspect of the relationship between New York and Miles's identity as Spider-Man-his simultaneous identities of being the abject "other" from New York, and yet, an inextricable part of it. This dynamic can also be observed visually in Miles's navigating the marginal structures of the city.

After acquiring his powers, Miles, like many superheroes, finds himself regularly traversing pieces of the city that were never intended for human traversal—particularly alleys and rooftops. These liminal spaces in the margins between the figurative and literal imposed structures of the city become the primary residence of Miles's identity as Spider-Man in these four issues. Before dawning the identity of Spider-Man, Miles regularly retreats into alleys when escaping the gaze of the city. On page 15, Ganke follows Miles into an alley where Miles has just vomited, which leads into their interaction on page 16. Though Miles made the decision to save the people in the burning building, the experience also revealed to him the consequences of being a superhero. The reader sees Miles in panel one leaning back against the dumpster, with just white space as the background (see Figure 6). This whitespace is replicated in the next two panels, and the final, borderless "panel," bringing the focus away from the city street and into this liminal space. Cast in shadow, Miles stands out from the background, and, in comparison to the busy panel compositions and page layouts of pages seven through fourteen, the only things depicted here consist of Miles, a garbage bag, and the dumpster. Such simplicity provides an opportunity for the reader to gain insight into Miles's character in this moment. Like Miles, the reader is encouraged to breathe, relieved of the input of the busy street. The street, the imposed 
structures of the city, and the people of the city demand so much, especially in respect to his powers and his compliance with the dispersed gaze required by the urban space. They demand that he uses his powers, to help people, and to exercise his unique ability to act outside of the

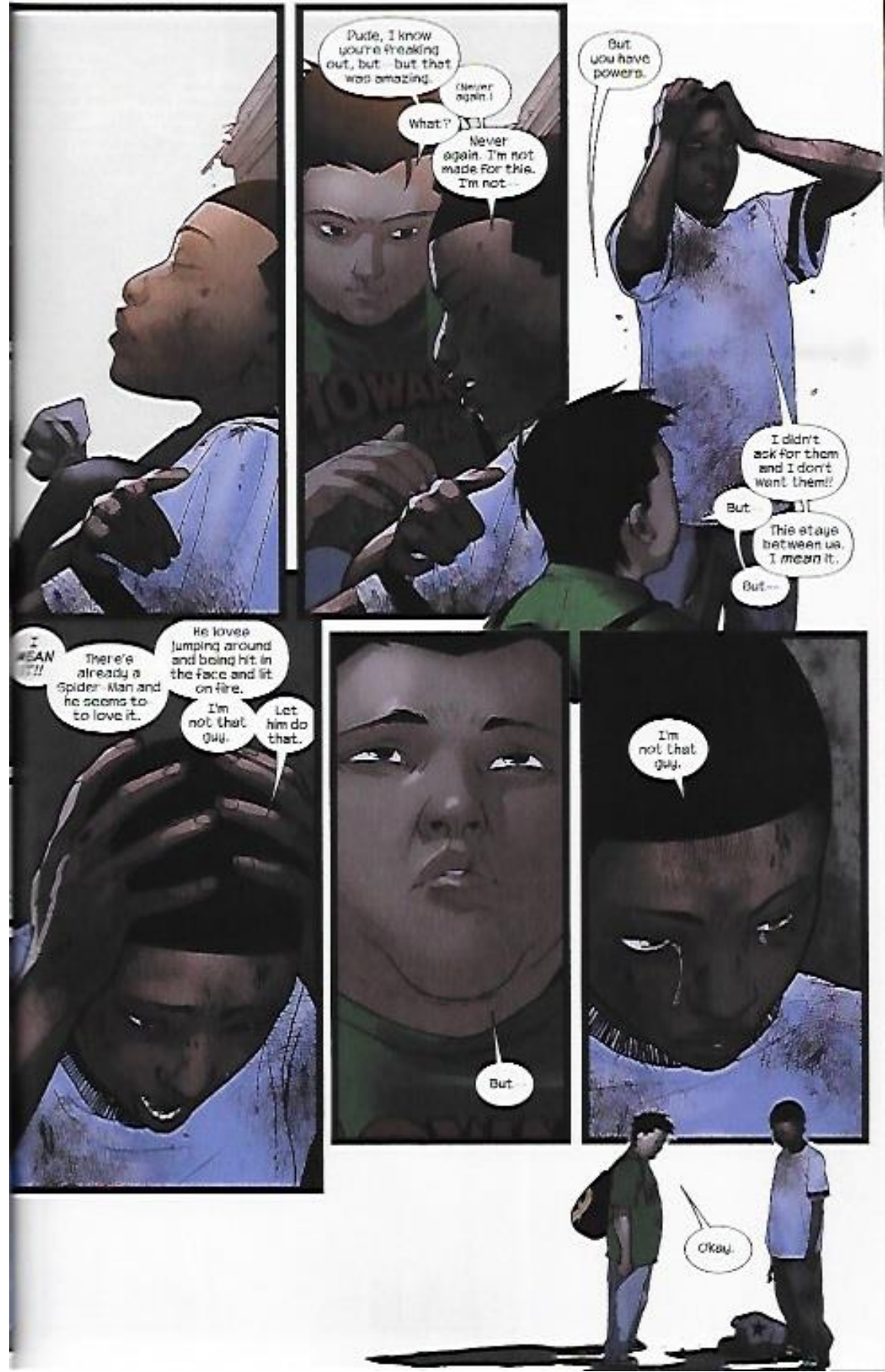

Figure 6 - Issue 3, Page 16 of Ultimate Comics Spider-man from Brian M. Bendis and Sara Pichelli; Ultimate Comics Spider-Man, Vol. 1. Marvel Comics, hegemonic norm to an

extent that the only safe

place for Miles to breathe

is in this alley, in the

margins of the city. After

panel two, where Ganke

reminds him of the events

that occurred, of the

impact he had in the

previous situation, that

liminal space is expanded

in the borderless panel

three. Here, part of panel

two is interrupted by

Ganke's body in the lower

left hand corner of panel

three, and Miles stands in

the borderless whitespace

shared with the whitespace

of the gutters. Indeed, the 
two of them stand literally in whitespace that is shared with the margins of the page. The use of the alley in combination with the panel breaks make the alleys of the city and the gutters of the comic synonymous with one another, implying that these particular physical margins act as points of respite for superheroes. The three panels that follow take on a far darker tone in comparison, but provide reinforcement for the bleak reasons Miles is refusing the superhero identity. In panel four, Miles explains that there's already a Spider-Man, that he seems to love "jumping around and being hit in the face and lit on fire. I'm not that guy. Let him do that." Miles describes the hardships endured by Peter Parker as Spider-Man, which demanded that he put himself in danger. As the fourth issue reveals, Peter Parker dies partially as a result of the demands of his identity as Spider-Man. Miles's somber tone is reflected in the grimey, low-lit, bleak background of panels four through six. The fact that the final "panel" consists of the rough figures of Miles and Ganke, again, standing in that same marginal, blank background, suggests that they are leaving the role and the demands of the superhero behind. It also suggests that the margins that exist as biproducts of imposed structure, outside the almost constant gaze of the city, similarly operate as both a part of and apart from the city as Miles's identity does. In this manner, Miles leans on these liminal spaces for moments to breathe, as he leans against the dumpster here and against a shadowy structure on a rooftop on page 22 .

In the wake of Peter Parker's death, Miles ultimately decides to dawn the superhero identity of Spider-Man, and his experiences in these marginal spaces take on a more optimistic and freeing tenor as they move from back alleys to rooftops. On page fifteen of issue four, Miles has dawned a Spider-Man suit for the first time and for the first time, allows himself to experience the freedom and the power of moving through the margins of society in this manner. In panel three, we see his silhouette against the setting sun, stretched in to a classic ballet-esc 
Spider-Man pose. Here, in comparison to those moments in the alley in issue three, Miles is surrounded by bright oranges and golds as he exclaims “Oh my God!! What was I waiting for!!?? This is amazing!!" Miles looks back on his hesitancy, on his delay with an attitude of
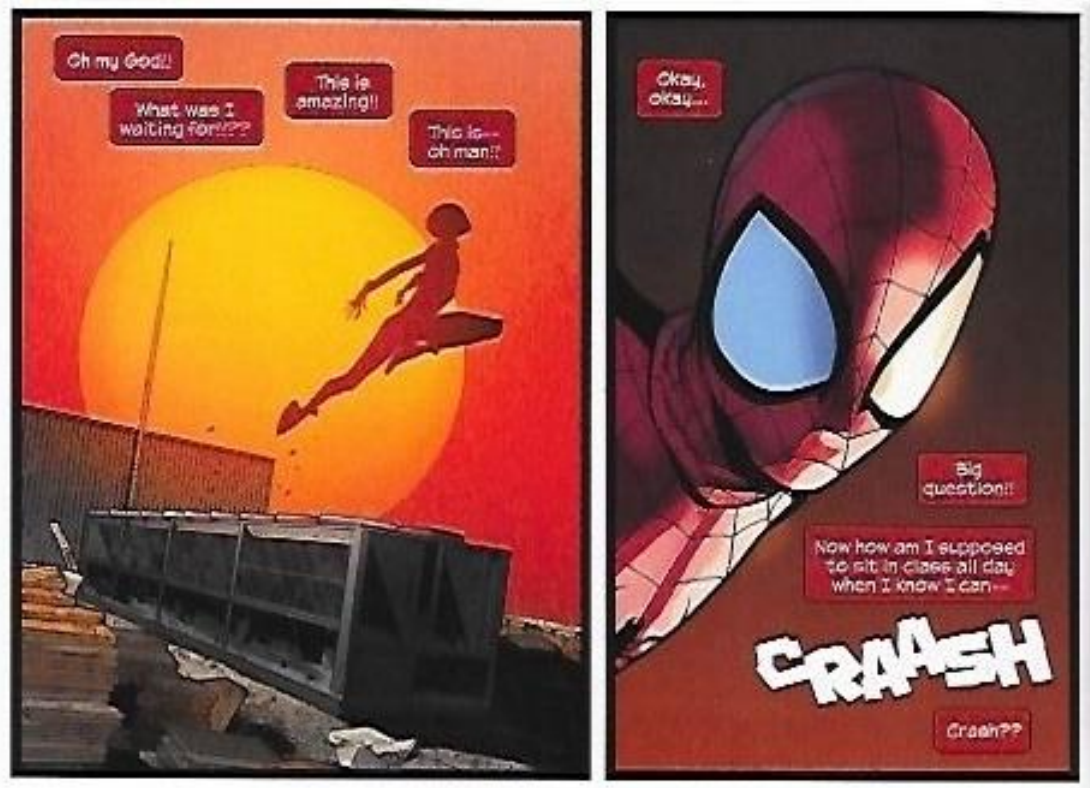

surprise and bafflement, because he's discovered benefits that accompany the responsibility of his powers and the vibrant, frenetic nature of Ponsor's colors and Pichelli's lines imbue the panel with the joyous basis of Miles's

Figure 7 - Issue 4, Page 15 of Ultimate Comics Spider-man from Brian M. Bendis and Sara Pichelli; Ultimate Comics Spider-Man, Vol. 1. Marvel Comics, 2012. sentiment. This is not to say that Miles maintains this energy through the whole of his career as Spider-Man. Indeed, just after the following fight with the Kangaroo, Miles takes to the rooftops again in a more reflective manner. Page 22 of issue four appears along with Miles's fight with the Kangaroo in Ultimate Fallout \#4, and it is the page that reveals the secret identity of this new Spider-Man as a young Black American boy. Again, the setting of this liminal, marginal space on the rooftop acts as a point of rest outside the urban space for Miles as he makes his way up and crawls to a leaning position in panels one, two, and three. And again, Miles is depicted (partially) outside of the fourth panel border and inside the whitespace of the gutters. A comparison between page 16 in issue three and pages 15 and 22 of issue four reveal that the visual emphasis of these liminal spaces through panel breaks appear in relation to a tone of uncertainty where Miles has 
something yet to overcome and to learn as a superhero. In addition, the fact that this acts as the first introduction to his character in Ultimate Fallout \#4 suggests that these liminal spaces could be crucial to the representation of Miles's superhero identity, his particular representation of Spider-Man.

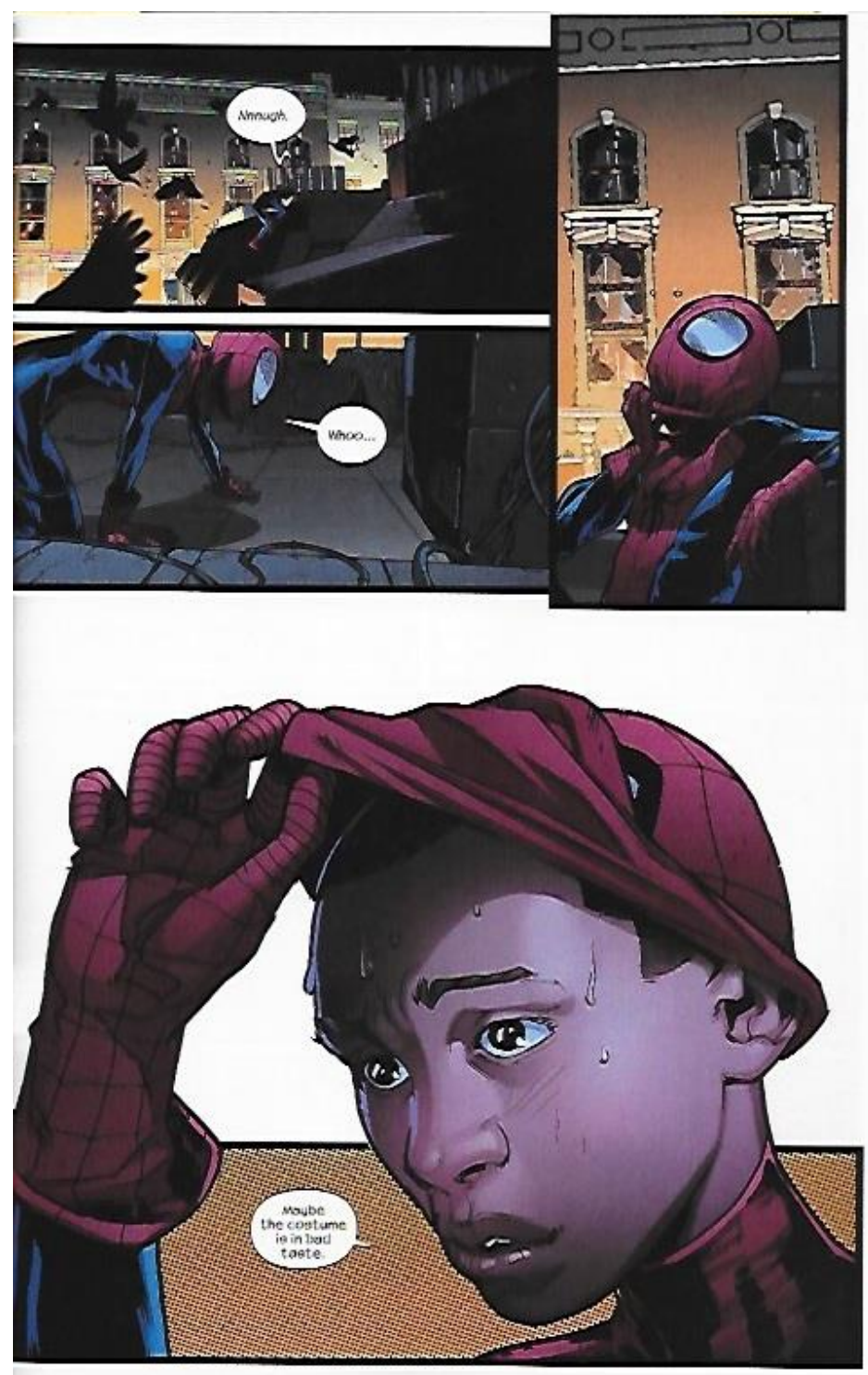

Figure 8 - Issue 4, Page 22 Ultimate Comics Spider-man from Brian M. Bendis and Sara Pichelli; Ultimate Comics Spider-Man, Vol. 1. Marvel Comics, 2012. 


\section{Conclusion}

These first four issues of Miles's story understandably establish a basis for the themes his particular journey will explore in Marvel Comics. These themes, nevertheless speak to the relationship between the superhero identity and urban space that could apply to other cases. That being said, all of the various Spider-People in the Marvel Multiverse demonstrate different intertwining relationships between New York city and their superhero identities. As Bainbridge explains in his examination of Peter Parker, the Spider-Man identity is particularly enmeshed with New York. Through this, I predict that Miles's particular ties to New York gave me a particularly clear and evidence-filled relationship to investigate as a researcher than many other superheroes would have. It is thanks to this deeply intertwined web connecting superhero and cityscape that I was able to discern some possible reasons as to how an urban space serves the (in this case, specifically Marvel) superhero genre. And much of those reasons find their basis in the unique way a in which city is structured. Due to the principal definition of the city, the density of population, the physical and figurative structures developed in response to dense populations in turn created spaces both a part of and apart from the city, spaces that help define the nature of Miles's role as a genetically altered person and as a superhero. Ultimately, the three main manners in which Miles's identity is tied to urban space-through the gaze and collection of crowds, through his powers allowing him to navigate the city subversively, and through the liminal spaces Miles frequently inhabits - culminate in a suggestion that Miles's superhero identity explores subverting figurative and literal hegemonic urban structures. This could suggest that the superhero identity at large is underlined by navigating metaphorical and physical marginal spaces and subversion of imposed structures both on a narrative and formal level. Urban space provides those structures and the density necessary to demonstrate a simultaneity of 
existence as a part of and apart from. These comics also display that through Miles embracing his superhero identity, he refuses to comply with the hegemonic norm. Miles effectively rejects the hegemonic gaze and dominant culture and embraces what his society shames. Unfortunately, my findings do not necessarily speak to Miles's identity as a Black Latino boy because these four issues do not expend much time explore those aspects of his identity. That being said, in a time when, more and more, the comics industry continues to present superheroes with marginalized identities, the connection must be made between the power of superheroes to navigate these physical and figurative margins and the power and hardships of marginalized individuals to act outside the imposed structures of society and subvert hegemonic norms. This is not to say that Superheroes are marginalized in the manner that Black, Latinx, Asian, Disabled, or LGBTQIA+ people are marginalized. Rather, Superheroes are symbols of hope and empowerment for those who must navigate the world through the margins, making it all the more important that Miles's Spider-Man looks after Ultimate Marvel's New York City, emblematic of the powerful link between heroes from the margins of the Superhero Comic and the heroes from the margins of society. 
Bibliography

Primary Sources

Bendis, Brian Michael, and Sara Pichelli. Ultimate Fallout \#4 : Spider-Man No More, Poly Bagged Edition. 4 edition, Marvel Comics, 2011.

---. Ultimate Comics Spider-Man, Vol. 1. Marvel Comics, 2012.

Secondary Sources

Coogan, Peter. Superhero: The Secret Origin of the Genre. MonkeyBrain Books, 2006.

Badman, Derik A. "Talking, Thinking, and Seeing in Pictures: Narration, Focalization, and Ocularization in Comics Narratives.” International Journal of Comic Art, vol 12, no. 2-3, 2010, pp. 91-111.

Bainbridge, Jason. “'I am New York'—Spider-man, New York City, and the Marvel Universe." Comics and the City: Urban Space in Print, Picture, and Sequence, edited by Ahrens, Jörn, and Arno Meteling. Continuum, 2010, pp. 163-179.

Balzer, Jens. " 'Hully Gee, I'm a Heiroglyph-Mobilizing the Gaze and the Invention of Comics in New York City." Comics and the City: Urban Space in Print, Picture, and Sequence, edited by Ahrens, Jörn, and Arno Meteling. Continuum, 2010, pp. 19-31.

Eisner, Will. Comics and Sequential Art: Principles and Practices from the Legendary Cartoonist. W. W. Norton \& Company, 2008.

Frahm, Ole. "Every Window Tells a Story: Remarks on the Urbanity of Early Comic Strips." Comics and the City: Urban Space in Print, Picture, and Sequence, edited by Ahrens, Jörn, and Arno Meteling. Continuum, 2010, pp. 32-44. 
Hatfield, Charles. "Ways of Reading Comics: A Page from Black Widow." California State University, Northridge, 26 Sept. 2016, https://www.csun.edu/humanities/comics/waysreading-comics-page-black-widow.

Highmore, Ben. Cityscapes: Cultural Readings in the Material and Symbolic City. Palgrave Macmillan, 2005.

Jarenski, Shelly. "Invisibility Embraced: the Abject as a Site of Agency in Ellison's Invisible Man.” MELUS, vol. 35, no. 4, 2010, pp. 85-109.

Loeb, Jeph and David Finch. Ultimatum \#1: Three Kings. Marvel Comics, 2008.

McCloud, Scott. Understanding Comics : The Invisible Art. William Morrow, 1993.

Persichetti, Bob; Peter Ramsey, Rodney Rothman. Spider-Man: Into the Spiderverse. Sony Pictures Releasing, 2018.

Rosenberg, Robin S., and Coogan, Peter M. What Is a Superhero? Oxford University Press, 2013.

Steirer, Gregory. "The State of Comics Scholarship: Comics Studies and Disciplinarity." International Journal of Comic Art, vol. 13, 2011, pp. 263-285. 